\title{
Posttraumatic pseudomenigocoele of cervical spine in a patient with skeletal fluorosis. Case report
}

\author{
V S S V Prasad MS Mch, ${ }^{1}$ D Raja Reddy FRCS FRACS FICS ${ }^{2}$ \\ ${ }^{1}$ Assistant Professor, ${ }^{2}$ Professor, Department of Neurosurgery, Nizam's Institute of \\ Medical Sciences, Punjagutta, Hyderabad 500 482, India.
}

A case of fluorotic cervical compressive myelopathy precipitated by trauma is reported. The delayed neurological deterioration was due to a posttraumatic pseudomenincocele, the prompt treatment of which resulted in recovery. Posttraumatic pseudomeningocele is very rare; and certainly so in fluorosis, and thus has not been reported in the literature to date.

Keywords: cervical myelopathy; fluorosis; pseudomeningocoele; post trauma.

\section{Introduction}

Neurological manifestations of skeletal fluorosis are mainly mechanical in nature although in the advanced stages secondary vascular changes may supervene. ${ }^{1}$ The cervical cord is more commonly affected than elsewhere in the spine. In some of these patients trauma may precipitate a neurological deficit. ${ }^{2,3}$ Because of the rigidity which occurs, traumatic disc prolapse, fracture and fracture-dislocation of fluorotic spine are uncommon. Similarly posttraumatic pseudomeningocoele is extremely rare and has not been reported in the cervical region which is the part most often injured in the spine. In our wide experience of the management of fluorotic spinal compressive myelopathy we have not until now encountered a pseudomeningocoele. In fluorosis the injury has to be severe enough to fracture the ossified ligaments all around the spine and the sclerosed bone to produce such a lesion.

\section{Case report}

A sixty year old man, a known diabetic, fell into a 30 foot deep well and presented with quadriplegia and a history of transient loss of consciousness. There was no clinical evidence of craniocerebral injury, except for $8 \mathrm{~cm}$ long scalp laceration in the left frontal region with partial tissue loss. When admitted there was sensory impairment below $\mathrm{C} 4$ segment and re- tention of urine. Neck movements being painful, immobilisation in a cervical collar was carried out.

Plain roentgenology of the skull was normal, but of the cervical spine revealed marked fluorotic changes and a fracture of C6. Ossification of the posterior longitudinal ligament (OPLL) was seen (Fig 1). He was suspected of having fluorotic cervical canal stenosis with compressive myelopathy, precipitated by trauma, and he had conservative management with steroids initially for a week. The patient recovered from spinal shock and neurologically remained unchanged with a spastic quadriparesis. The power in the upper limbs was grade $2 / 5$, and in lower limbs grade $4 / 5$, with sensory impairment below $\mathrm{C} 4$. Routine radiology showed ossification of the ligaments of the pelvis, spine, and the interosseous membrane of the forearm, characteristic of fluorosis. Plain CT revealed hyperdense vertebrae with fractured laminae of C5 and C6 and OPLL (Fig 2). There was a hyperdense soft tissue mass over the fractured posterior elements. MR imaging was done as part of investigation of fluorosis as well as for the spinal cord injury; the vertebral bodies showed hypointense signals characteristic of fluorosis. There was a soft tissue mass in the posterior paraspinal region which was tissueisointense with cerebrospinal fluid (CSF) (Fig 3). The spinal cord showed contusion at C7 level.

As the neurological recovery was static even after a period of 3 weeks and as the shoulder muscles were becoming weak, with the above radiological evidences of OPLL and a tense pseudomeningocoele, surgery was decided on. At operation, the characteristic changes of a 


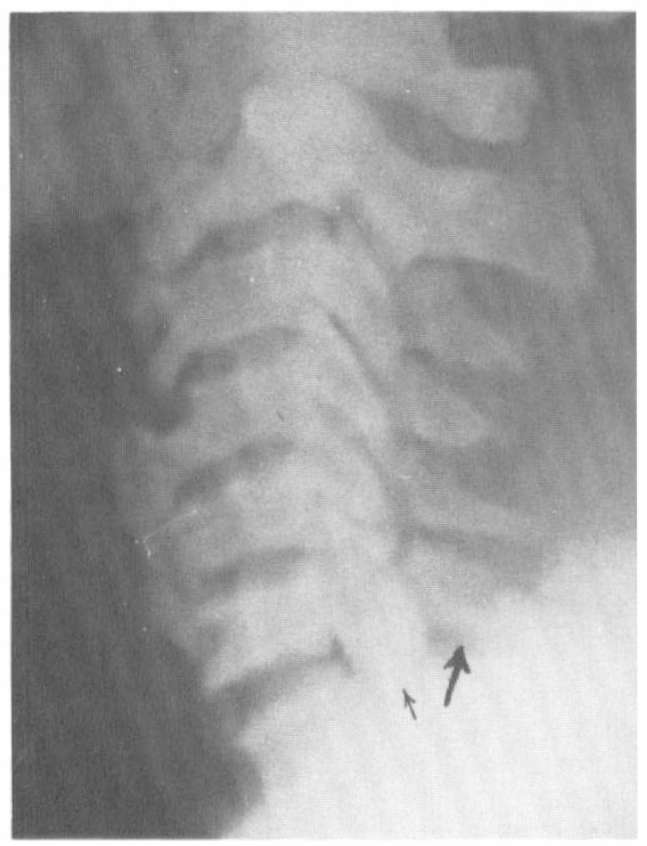

Figure 1 Plain radiograph of the cervical spine demonstrating the typical hyperdense fluorotic changes with abnormal ossification.

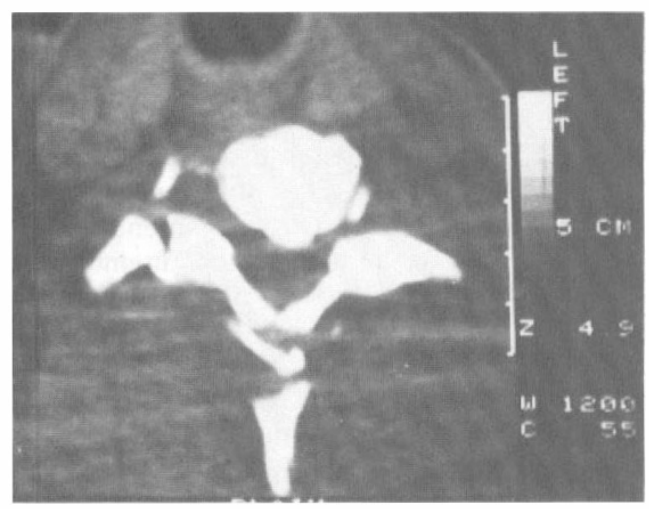

Figure 2 CT scan of the cervical spine showing the fluorotic bone and the fractured posterior elements.

fluorotic spine were observed in the form of ossified spinal ligaments and hardened bone. There was a fracture of the C6 spine and also of the laminae, and CSF was found flowing from an intraspinal pouch that was entering the spinal canal between $\mathrm{C} 5$ and $\mathrm{C} 6$. The spine was like a continuous column of bone, typical of

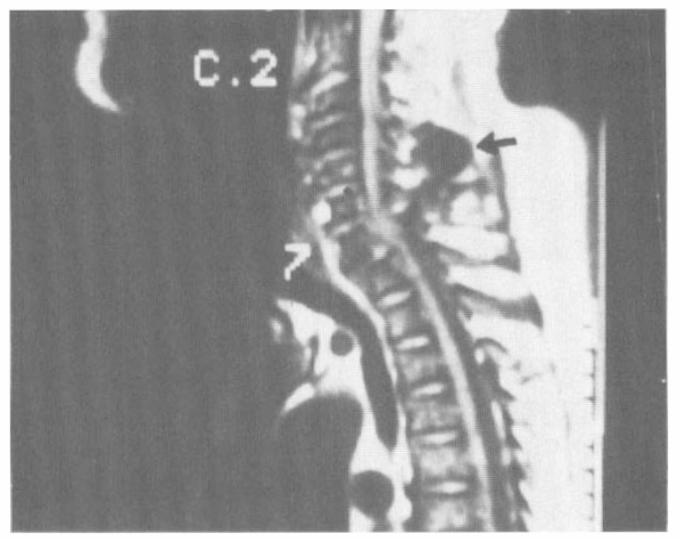

Figure 3 MRI of the cervical spine, sagittal section, T2-weighted image, which delineates the soft tissue mass with CSF intensity. Cord contusion is also seen.

fluorosis, except for the above area of breach. A C2-7 laminectomy was performed to visualise a well decompressed, pulsatile dural sac.

Following excision of the pseudomeningocoele, no active CSF leak was observed; a small dural rent was repaired. Postoperatively the spasticity in the lower limbs disappeared and power improved gradually after physiotherapy. At the time of of discharge the patient was ambulatory with a cervical collar support.

\section{Discussion}

Fluorosis, a term coined and used by Cristiani \& Gautier in $1925,{ }^{4}$ was first mentioned in man as an occupational disease by Feil in $1930 .{ }^{5}$ It is now known to be endemic in parts of India with occasional reports from other parts of the world ${ }^{1}$ fluoridation to prevent dental caries playing a major role. ${ }^{6}$ It has been estimated that 25-30 million people are exposed to the risk of developing fluorosis, and half a million people suffer from it in our country.

In man, the spine is the most common part of the skeleton to be first affected and also severely so because it is required to sustain the erect posture and has stresses and strains. ${ }^{7}$ In severe and chronic cases various ligaments of the spine become ossified until the spine becomes a continuous column of bone. Neurological sequelae in 
skeletal fluorosis manifest as radiculomyelopathy, principally due to mechanical compression of the spinal cord and nerve roots by the above changes. ${ }^{8}$ Only late in the process may secondary vascular complications supervene. In about a tenth of the total skeletal fluorosis cases neurological complications set in at a late stage and commonly involve the cervical region. ${ }^{2}$

Though the disease develops slowly with relentless progression, the neurological manifestations may sometimes be precipitated by minor trauma. ${ }^{3}$ Nervetheless, trauma producing major bony injury or discal herniation is uncommon. Similarly posttraumatic pseudomeningocoele formation is rare, although postoperative meningocoele can occur, and the formation of a meningocoele following root avulsions of the lumbar and brachial plexuses are also described. ${ }^{9}$ However, a pseudomeningocoele producing spinal compression following trauma has rarely been reported (Table I). ${ }^{10-12}$ The fourth incidence was due to tranverse fracture of the sacrum. ${ }^{13}$ To our knowledge this is the first reported instance of a pseudomeningocoele following fracture of the cervical spine without transection of the cord and especially in fluorosis. We propose that a spinal injury in flexion occurred with the severe impact to the left frontal region, producing a fracture of the posterior spinal elements and a tear in the dura, which was in close proximity to the bony elements due to the associated spinal canal stenosis. Direct trauma to the neck with flexion and axial loading is another possibility. A dural tear in a closed spinal injury led to the formation of a pseudomeningocoele as may happen postoperatively. We stress the usefulness of the diagnostic imageology of computed tomography (CT) and magnetic resonance imaging (MRI) in these cases. Apart from the demonstration of the fluorotic changes in the spine, the epiphenomena, like pseudomeningocoele in the present case, are delinated with clarity by MR tomography. Surgical management consists of an extensive laminectomy when the compression is from the posterior, and corpectomy with fusion in patients with localised compression from the front.

Table I Papers in the literature pertaining to spinal column fluorosis

\begin{tabular}{lcccc}
\hline Authors & Spine level & Cord lesion & $\begin{array}{c}\text { Age of patient } \\
(\text { yrs })\end{array}$ & Year \\
\hline Zilkha et al l11 $_{\text {Osaka } \text { et } \text { l }^{12}}$ & T3 T4 & Transection & $4 \frac{1}{2}$ & 1970 \\
Cook et al $^{10}$ & T4 & Transection & 5 & 1980 \\
Present & T2 & Transection & $6 \frac{1}{2}$ & 1989 \\
\hline
\end{tabular}

\section{References}

1 Raja Reddy D (1979) Skeletal fluorosis. In: Vinken PJ, Bruyn GW, editors. Handbook of Clinical Neurology. North Holland publishing Co. Amsterdam: 465-504.

2 Jolly SS, Prasad S, Sharma R (1973) Endemic fluorosis in Punjab-skeletal aspect. Fluoride 6: 4-18.

3 Jolly SS, Singla VP, Sharma R (1974) Endocrine aspects of endemic fluorosis. Fluoride 7: 208-2.

4 Christiani H, Gautier R (1925) Emanations fluorées des usines eude expermentale de l'action du fluor sur les vegetaux. Ann Hyg Pub (Paris) 3: 49-64.

5 Feil A (1930) Le fluorisme professionel. Intoxication professionelle par l'acide fluohydrigue at les sels fluor. Paris Med 2: 242-248.

6 Colquihoun J (1984) Disfiguring dental fluorosis in Auckland, New Zealand. Fluoride 7: 234-41.

7 Murray MM (1950) Industrial fluorosis. Br Med Bull 7: 87-89.

8 Singh A, Jolly SS (1961) Endemic fluorosis with particular reference to fluorotic radiculo-myelopathy. Q J Med 30: 357-372.

9 Nashold BS, Higgins AC, Blumenkopt B (1985) Dorsal root entry zone lesions for pain relief. In: Wilkins RH, Rengachery SS, editors. Neurosurgery. 1st edn. McGraw-Hill Book Co. New York: 2435. 
10 Cook DA, Heiner JP, Breed AL (1989) Pseudomeningocoele following spinal fracture. A case report and review of literature. Clin Orthop 247: 74-79.

11 Zilkha A, Reiss J, Shulman K, Schecter MM (1970) Traumatic subarachnoid-mediastinal fistula. J Neurosurg 32: 473.

12 Osaka K, Handa M, Watanabe H (1981) Traumatic intrathoracic meningocoele (traumatic subarachnoidpleural fistula). Surg Neurol 15: 137.

13 Hadley MN, Carter LP (1985) Sacral fracture with psuedomeningocoele and cerebrospinal fluid fistula. A case report and review of literature. Neurosurgery 16: 843. 